\title{
The rhetoric of organizational stability and creativity: an analysis of the term 'platform'
}

\author{
Larry D. Browning \\ Department of Communication Studies \\ The University of Texas at Austin \\ Bodø Graduate School of Business \\ The University of Nordland \\ Email: Ibrowning@mail.utexas.edu
}

\section{Joseph Brentlinger}

Department of Communication Studies, University of Texas at Austin

Email: jbrentlinger@gmail.com

\section{Jan-Oddvar Sørnes}

Bodø Graduate School of Business

The University of Nordland

Email: Jan.Oddvar.Soernes@ hibo.no

\section{Keri K. Stephens}

Department of Communication Studies

University of Texas at Austin

Email: kstephens@austin.utexas.edu

\begin{abstract}
This article analyses the term platform as it surfaced in interview data from Norway and the United States that was collected in a field research project on organizational technology use. Through an inductive analysis of the term's use in six interviews, a conceptualization of the term reveals it to be rhetorical in nature, expressing the interplay between stability and creativity. In order to explain the rhetorical aspects we describe, the authors turn to the rhetorical critic Kenneth Burke's work to aid in conceptualizing the term, specifically his understanding of scene and agency. The authors present the conceptualization to help researchers on two levels. On the micro-level, we offer an analysis of the term platform. On the macro-level, we illustrate how grounded theory can help locate other terms that have unacknowledged salience to researchers, consultants, and interviewees.
\end{abstract}


Keywords: platform, inductive, stability, creativity, scene, agency, communication, organizations, Burke

\section{Introduction}

This article analyses the usage of a single word-platform-to illustrate that communication relies upon what we call the two tenets of creativity and stability. More specifically, we analyse the usage of the term in six specific instances of contemporary organizational communication to illustrate that technology's relationship with communication is not merely a means to acting in the world, but can also constitute the scene upon which communication is played out. Because communication relies upon creativity and stability, our inductive method of analysis leads us to the rhetorical critic Kenneth Burke's understanding of agency and scene.

Nearly a decade ago, Waters (2005) noted that the term platform deserved attention, and, rather than podcast, should have been the New Oxford American Dictionary's Word of the Year for 2005 due to its ubiquity. The term continues to grow in popularity, and as Ashforth and Humphrey (1997) say about a label that has such prominent usage, it influences how individuals understand-and therefore communicate-a particular social object. Orlikowski (2009) argues that platform is not merely a label for an organizational structure, 'but is integrally and materially part of constituting that phenomenon' (p. 14). The most prominent use of the term platform at present is for source code for computer software (Von Hippel \& Von Krogh, 2003), but that basic meaning was derived from a more historical usage of the term which has been expanded to include all kinds of concepts and structures. The expanded meaning allows one to use the term with relative ease and flexibility (Browning \& Morris, 2012).

For instance, Martin Sköld and Christer Karlsson (2007) have dealt with the managerial aspects of 'multibranded platforms' (p. 554), and Consoli and Patrucco (2008) have analysed technology platforms as they pertain to innovation. Ciborra (1996) analyses the Olivetti Company of Italy as a platform organization, conceiving the term broadly when he observes that the company has the ability to adapt quickly 'to sport whatever organizational form is required under the circumstances' (p. 103). Olivetti has a concern for efficiency and reliability in its structures. Because Olivetti has standards for products, they can be recombined from disparate elements 'at the last minute' into a bundle to meet the 'specific products required by the market' (p. 112). Ravasi and Schultz (2006) conceive the term more finitely, using the term platform as an interface between Weickian sense-giving and sense-making (pp. 452-3). In these examples, meaning is added (and some meanings are eschewed) when the term is used in novel ways for particular situations. But whereas others have analysed corporations as platforms, we turn to the term platform itself to illustrate that the word simultaneously communicates a powerful symbolic meaning and provides practical solutions for organizations.

Our purpose in this paper is to examine the term platform in detail by our analysing a collection of examples that illustrate how the term is used to communicate a combination of stability, order, and reliability as a shifting companion to creativity, movement, and speed. Concerning the term platform, 
Gawer states that 'the research on industry platforms builds on several distinct literatures, which hitherto had rarely been brought together', citing 'engineering (Ulrich, 1995; Baldwin \& Clark, 200); organizational literature on modularity (Sanchez \& Mahoney, 1996; Schilling, 2000), with economics literature on standards and network externalities (Kaz \& Shapiro, 1985; Shapiro \& Varian, 1999)'; as well as 'strategy research on new forms of industry dynamics mixing competition and co-operation (coined as 'co-opetition', see Brandenburger \& Nalebuff, 1996)' (Gawer, 2010, p. 288). We add to this list Communication Studies, since Kenneth Burke's work offers us insight into the term platform because it sits astride two grand dimensions of his theoretical work: agency and scene. If an organization is too fixed and unresponsive, it will wither and be replaced by a new and more flexible one (Hirschman, 1970). Yet if an organization is only focused on creativity and flexibility without commercializing and routinizing its practices, all the novelty in the world simply goes to waste, failing in its endeavour (Jolly, 1997; Porter, 1995).

We believe our scholarly intervention works on two strata: the micro-level and the macro-level. On the micro-level we offer this article as an analysis of the term platform, and how that analysis may help researchers and consultants. For example, if a person is relying excessively on the stability he or she is being offered, then the researcher or consultant might suggest relying more upon creativity. But we also believe that this article works on the macro-level. Researchers and consultants might-through the inductive process that grounded theory allows-find other words that reveal rich sources of theoretical and practical knowledge. These researchers could then use the inductive method on different words that surface in interviews, and follow where those words take them to make novel, meaningful interventions themselves.

The remainder of this essay attempts to show how the term platform connotes the interplay between scene and agency, what we are calling stability and creativity. The first section will detail our research protocol and reasoning. The next six sections are case studies that detail the term platform in its everyday use. The last sections will discuss the cases and explain the complex interplay between agency and scene, what we call the negotiation between creativity and stability.

\section{Research protocol and data analysis}

After analysing 66 interviews (half from Norway, half from the United States) to identify 20 to rewrite as narratives on the practice of using InformationCommunication-Technologies (ICTs) in the workplace (2008), we completed an additional QSR NUD*IST software search for additional themes, noticing that the term platform reoccurred in the data set in six quite different places in a manner that no other distinctive term did. We conclude that the most appropriate way to represent these six cases is to bundle them and treat them as a sensitizing concept, or, something in the data that sparks a thought by the researchers (van den Hoonaard, 1997) and allows them to expand on that idea.

In qualitative research a sensitizing concept is an idea that appears in the natural language of the field being studied and as a result invites the researcher to explore its theoretical depth. We do so here when we take an 
idea surfaced by the interviewees themselves, then inspect and dimensionalize the concept inferred and make linkages to other contexts (van den Hoonaard, 1997). We follow this guidance and link the term platform to an analysis of stability and creativity in organizations by showing how the term represents a communicative force that affects order and variety in organizations.

Ultimately we take a grounded approach in this essay (Glaser \& Strauss, 2011), deriving our conceptualization of the term platform from an inductive analysis of the term in its use. By analysing similarities and differences between the cases, we find that each instance of the use of platform in our examples leads us to conclude that when the word is invoked, it connotes a strange interplay between stability and creativity. This peculiar interplay indicates that people require the means not only of enacting meaningful communication, but also of grounding through communicatory practices that can provide a stable means of fact-checking, that is, of being able to make assertions and then to point to their validity.

Because of the dual dimensions of creativity and stability inherent in the term's usage, we turn to Burke's rhetorical approach. His body of work is immense (works of his were published from 1931 until after his death in 1992) but here we describe only two small aspects of his broad range of thought-scene and agency-because his theorizing on these two terms correspond with our own ideas concerning the dual aspects of the platform: stability and creativity.

Burke's most explicit contemplation on the concepts scene and agency are found described in his work, $A$ Grammar of Motives. The idea of scene itself is rather simple, being either the 'environment' where action takes place, or the background that helps to explain actions in a meaningful way (Burke, 1969). In his analysis of the concept, Burke places all materialist philosophies (Marx, Darwin, et al.) under the heading of scene (p. 128). Agency, however, serves to answer how people act in an environment, or the means by which they do so (Burke, 1969). Agency in its usual scholarly usage is meant as the ability to act as one means to do in the world. In Burke's sense, however, agency is to be understood as a technology for action, as the thing that allows one to act. Under his analysis, Burke would place philosophies such as pragmatism (Dewey's, James', etc.) under the rubric of agency (p. 128).

The case studies below detail different examples of the term platform in its average, everyday usage. They are rarely spectacular, but we believe that studying the usual often yields unusual observations. The examples showcase the term differently, and we track how the different uses indicate the complexity involved in maintaining a balance between creativity and stability. For example, sometimes the Internet or other communication technologies is the scene upon which communication is enacted; other times, it is merely the means of communication, and an office or hospital constitutes the scene; but at each turn a need for the negotiation between creativity and stability is implicated in the invocations of the term platform.

\section{We are Loyal to the Platform Chosen}

In this first case of the term's use, the platform Frank (all the names and organizations used here are pseudonyms) refers to a gives kind of consistency in the protocols for communication that requires a great amount of loyalty from 
its users. Adherence to protocol is so important because of the effort required to make a sale for Frank's company. Employees promote the company's distinctive offerings by using 'relations marketing', or more simply what Frank calls 'good, honest sales work'. The firm has approximately 650 clients that use products either bought online or billed by the hour as consulting services. The platform therefore works as a repository. It acts as a collection and storage device, one the one hand; but, on the other hand, it acts as a bulwark against data misuse or loss. He says of his communications, 'Everything I do is documented digitally-ranging from appointments, logging customer information, offers to customers, and other types of information used in the sales process. We store everything digitally, and throw away the hard copy.'

In response to a question about the most important communication principle in his organization, Frank says that primary importance is placed on 'loyalty to the communication medium, or mediums, chosen for the sales process. By that I mean, we have to be loyal to the platform chosen. That is, if we have agreed on a certain way to store information, or the entire communications process for that matter, it is important that everybody is loyal to that.' Sales persons both store information about the sales process and conduct further matters on the sale in a uniform fashion. Frank insists on exactly following this communication protocol because 'the system breaks down' the moment a colleague breaks the rules, and this infraction results in some sort of mistake.

For Frank's firm, fidelity to procedure is needed to allay any ambiguity. Something as rudimentary as taking minutes at a meeting and posting them online necessitates strict adherence to procedures previously agreed upon. Not having the stability of the protocol means that a colleague might, during a subsequent meeting, be expected to contribute some expert piece of information to which she or he has no access. But information retained in a procedural way safeguards against ambiguous situations: recording dealings with a difficult or volatile customer allows colleagues to build on what others have done, and then to make plans of action. At every turn, Frank's response to ambiguity is standardization: 'It is necessary to have a policy on this, not just a wish or statement from somebody.'

\section{LRN-TECH Offers a Learning Platform}

The term platform is placed at the core of Amanda's U.S. firm when she explains what they do. In response to a question about their product she says, 'LRN-TECH offers a learning platform', meaning they offer web-based training for their client's employees. LRN-TECH partners with the client, who provides proprietary subject matter and content, to set up training modules tailored for the clients' employees. LRN-TECH's product is offered on a platform in the sense that her company hosts 'the entire application' for the client firm, including the means to enter and experience the training and to monitor program use. The monitoring is used both to allow the client company to track compliance and for LRN-TECH to charge user fees.

Amanda is a salesperson and spends approximately three hours a day searching the Internet for qualified prospective clients. The searches are extensive, as she must make her judgements regarding client selection on the basis of criteria such as company size (LRN-TECH's services are best suited for companies of 1000 or more employees), maturity (start-ups have different needs than established businesses), and key players (who makes the decision 
to pay for LRN-TECH's services?). Her online computer time using a commercial search program allows Amanda to locate most of this information, but she also improvises and utilizes online boards of other resources (such as the American Society for Training and Development) to uncover useful information. In a recent search she discovered that a potential client had listed on the ASTD board the exact names of the other firms vying for offering their training services. As she stated, 'They would never have told me this information if I had asked for it directly'. In another instance, she was able to identify on a client's webpage for jobs their new openings so that she might have an idea of the training modules the potential client would require.

The time invested in qualifying clients is important because her firm's protocol is to move towards face-to-face meetings, but her firm only does so when it believes direct contact will result in an immediate sale. As she says, one of the easiest errors to make before the face-to-face encounter is to get 'happy ears' by misinterpreting what the potential client is communicating, and declaring them ready to close on a sale when the client is not ready to commit. Such an error not only wastes resources by travelling to attend the face-to-face meeting, but it can also backfire, causing a potential client to recoil, misdirecting the entire sales process. While the research process and client preparation are both nuanced, the platform itself is not. The learning platform is a stable, yet adaptable system that allows for the easy transfer of distinctive content that can then be accessed for particular clients.

\section{We are over on a New Platform}

Ivar is an Assistant Professor at a regional hospital in Norway, and he also works for Norway's National Centre for Telemedicine. Although he uses one computer to examine patients' electronic pathology charts, all other computer work (emailing and other routine work) is done on a completely separate PC. The security precautions necessary to protect the patient's electronic records and anonymity are too important.

Much of Ivar's medical diagnostic work is completed in the traditional manner, with his making his judgements on the basis of the patient's medical record, or occasionally consulting a colleague when difficult diagnoses arise and he would like a confirmation. In addition to these usual protocols he also uses PubMed, which is an international periodical database for medicine maintained and updated by the National Library of Medicine in Washington, D.C. There is a concerted effort in Norway to expand the breadth of experience in diagnosis, and the country has an intranet connection that allows all Norwegian doctors in Ivar's specialty to share information and even to complete remote analyses by controlling microscopes via computer controls.

Research is integral to Ivar's profession, and he uses the word platform simply to indicate a recent change in technology that alters the rules for 'read only' and open access to files: 'Now we are over on a new platform because we have changed software to an upgraded version.' He describes the access rights since the new platform was established: 'Guest members have readbut not write-privileges, while regular members have write privileges, and they can publish onto the intranet.'

Ivar complains that of the 100000 articles in medical journals, half of them should never have been published because their contribution is minimal. Also, 
he finds that there are too few review articles that give direction to finding reliable research because such reviews are 'hellish' work for doctors. He too bemoans the lack of adaptability some of his older colleagues display, especially their slowness to adopt newer communications technologies. For instance, Ivar describes the hospital's decision to invite doctors to board meetings only by email invitations to force them to utilize the tool. 'Those who missed the meetings', he says, 'because they didn't read their email, have no good reason'. Ivar also comments that doctors are slow to use technology, because they are accustomed to the tradition of talking directly together, and are reluctant to make judgements on distant records.

\section{Searching for a Platform}

Vegar is an administrator at a regional university in Norway who handles communication tasks associated with the web, including both sending and receiving messages about the tasks to disparate members of university management. He talks about platforms when he assesses communications products that offer something innovative while meeting university standards. Vegar must also act as the contracting agent for university publications on such items as handbooks, brochures, class schedules, and other documents that are printed in large numbers. He publicizes the specifications for bids and then follows up to assure that contractors in fact have the capability to deliver what is needed before he signs the agreement.

Vegar's responsibilities means that he acts as evaluator and protector of his institution's image by making sure that the paper type and colour, as well as the logo, of the university's official printings is properly represented on documents. He compares the various printing offers when there are competitive bids. He reviews printing work from individual academic departments who provide their own information for publications such as schedules, class offerings, and so forth. He assures that the publications submitted by the individual departments for printing conform to a single quality standard. His project-funding list is drawn from a university document that lays out its priorities in a strategic plan that the University Board approves each fall. In addition to reviews of his work as a communications manager on these projects, he also has to prepare for and to pass state audits that prove his documenting competence.

This standard by conformity means that his search for various solutions is tied to particular platforms. But since he is not a programmer, his attention is directed towards the 'structure and presentation of information that goes on the web', including its interactive services. To complete the contracting for services, his pattern of communication is well established. He meets with people he is working with for the first time or on big projects in face-to-face meetings to get a feel for what they are about. He then turns to managing that relationship through email because it saves time, offers detail, provides a record of interchanges, and allows for follow-up editing and other kinds of changes. When Vegar says he is searching for a platform, he is looking for programs that allow him to meet each of these demanding needs. 


\section{Want a Stable Platform}

John's work requires him to search the Internet and then translate what he finds into useful information for his employer. When he says he wants 'a stable platform' he is merely commenting on the qualities a Mac versus a PC platform as his preferred tool for producing graphics for presentations. Prior to his current career, he was in the U. S. Air Force (USAF), and he speaks with pride as he says, 'I spent 20 years in the military, and at SAC (Strategic Air Command) headquarters I was a staff officer. That's the kind of job I really like. You need something, you go get it done.' John now spends from five to ten hours a day on the Internet and he is comfortable 'going in and saying, Okay, this is a good company; this doesn't seem right; this does.' As well as 'A lot of it is dated, old. You know, it may be good data, but it's no longer credible.'

John sees himself as a functionalist with a tool for every task. For example he offers - without solicitation-great detail about his goal-oriented approach, one that allows him to assemble 30-second 'elevator pitches', to design trainings, to create logos for new companies, and to craft just the right message to communicate to potential customers and his superior. In his interview, John is direct and specific about every step that he takes as a technical communicator, and he often summarizes a plan as having the potential to 'blow apart' a market they are entering.

He represents his ability to complete this work by describing the tools he chooses for a particular job. John's preferences are somewhat typical in that he uses a Mac at work and a PC at home to take advantage of the best of each system. The Mac graphics platform is crucial to his primary task of communicating his findings to the CEO of his company, who prefers a PowerPoint presentation with all the key information represented in graphics. He says of his boss, 'He's a tinkerer, and it's best to present him graphics. $\mathrm{He}$ works best with that, and let him play with it, look at it for a while.' John says his boss has a noticeable pattern and that an hour or two after receiving the information, 'he'll start bringing ideas back and we'll change things-over a day or two'. John has learned not to send his boss typed messages because 'textual [matter] with him takes a little longer-he just doesn't have time to read it all'. John simply sends him information 'in quick little bursts via email, and then wait[s] a day or two' for a response. When John comments that he wants a stable platform, he is saying that he is so adaptable and has so much task variety that he wants to give dependable order to his dynamic job.

\section{Mapping competencies onto a platform}

The term platform is used at Norwegian HR-360 to represent a person's career path 'mapped' onto a document. HR-360 sells a human resource (HR) model that captures the employee's abilities through testing, then documents the employee's varied resources and skills. Key to the product's success is the individual employee's accepting this summary document as the official record of her or his ability. The document is viewed in totality from a 'life-long learning perspective' that encourages people to own and 'actively develop their own career' The HR-360 model assumes that there is an incentive 'for the employee to update the information', ensuring that the individual's and HR360's interests are commonly allied because it lists an individual's 'competency IQ' in modules that are valuable for the company. 
HR-360 serves three different client segments: oil and gas, the public sector, and banking and finance. Like other consulting firms, HR-360's success depends on selling its service. They pursue this goal by having sales representatives in two different cities in Norway, and by allocating much of their top company leaders' time towards closing deals. While the platform is intended to provide stability for the employee, the client company, and HR-360 itself, the sales process that leads up to 'closing a client' is anything but stable. The sales process is constantly changing, which then necessitates adapting quickly to expectations and stylistic changes. HR-360 uses the Internet to establish its corporate presence and to communicate a particular competence by identifying key words from other websites and showcasing these words as their own. The purpose is to demonstrate that they know and can accurately articulate the jargon of the human-resource industry. The platform emphasizes stability, but the sale of that platform is mercurial.

\section{Discussion of Cases ${ }^{1}$}

Thus far our claims have been: 1) communication is based upon the ability to manage or balance creativity and stability in order to make meaningful contributions in the world; 2) that creativity is a kind of agency, while stability is a kind of scene in the Burkean sense, and; 3 ) that by analysing the term platform in its everyday use, we can see how the two tenets of creativity and stability work themselves out in organizations to create meaningful solutions to challenging problems.

We find more evidence for our understanding of the term platform as a combination of scene and agency, stability and creativity, in the etymology of the word itself. Platform is a composite of two shorter words, and the first, plat, stems from the Old French word 'plot', meaning a piece of ground. 'Plot' is

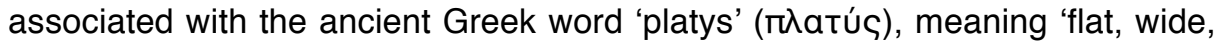
broad'. Plat is a root word for a variety of current words associated with stasis: place, plaza, piazza, plate, platter, plaque, plot, plan, placenta, placid, plateau, placard. The Latin and ancient Greek root plac- (п入ак-) simply means flat. The many meanings encompassed by these words create a large background in the Burkean sense for the concept of a platform. Similarly, the English word form stems from the Latin word forma, meaning to 'form, shape, mold, case; the first instance of form occurred in $1225^{\prime} .^{2}$ To form is analogous to agency, and in Burkean readings, this is important. $A$ form, from a narrative standpoint, works to intrigue and satisfy-and often conveys experiential kinds of knowledge. It can be repetitive or brand new, but it is inevitably designed to bring about predictable results and reactions: "basic forms may, for all that concerns us, be wholly conventional. The subject-predicate form of sentence,

\footnotetext{
${ }^{1}$ An easy reference table (1) summarizing this section follows the conclusion of the article.

${ }^{2}$ Entry downloaded July 1, 2012. '1550, "plan of action, scheme, design," from M.Fr. plate-forme, lit. "flat form," from O.Fr. plate "flat" (see plat) + forme "form" (see form). The literal sense of "raised, level surface" is first recorded 1560. Political meaning, "statement of party policies," is from 1803, probably originally an image of a lit. platform on which politicians gather, stand, and make their appeals, perhaps influenced by earlier sense of "set of rules governing church doctrine" (first attested 1573). Railroad station sense is from 1838.' (http://www.etymonline.com/index.php?term=platform)
} 
for instance, has sanction enough if we have learned to expect it. It may be "natural" only as a path worn across a field is natural. But if experience has worn a path, a path is there-and in using the path we are obeying the authority of a prior form' (Burke, 1931, p. 142).

These six cases indicate that the term platform contains a plurality of connotations. In them, platforms are described as the means through which learning, searching, mapping, stabilizing, adapting, and standardizing occurs within organizations. However, all six of the term's description can be understood as disparate ways organizational members manage and balance the two aforementioned dimensions of stability and creativity.

We present our first two cases-that of Frank's consultancy firm and Amanda's online training firm-next to one another because each exemplifies one of our terms over-determining the other. In Frank's case, it is agency that helps to dictate the scene, whereas with Amanda's case, it is the scene that helps to dictate the means of agency.

In Frank's case, the means of communication helps constitute the consultancy firm's understanding of the scene. We take seriously the idea that, to those in the firm, loyalty to the communication medium becomes synonymous with being loyal to the platform chosen. Also, we find a link between these statements and the fact that everything is stored digitally, while the hard copies are thrown away. Communication becomes the means of stability, and therefore creativity is restricted, after the agreement has been made on how things ought to be done with regard to communicating with a particular client. We find three reasons for this restriction. The first is the nature of the business: as a consultancy firm, what is being sold is largely communicative in nature, in the form of agencies designed to help clients and organizations. That the firm's business is selling something seemingly ephemeral is not to be ignored. Second, the restriction of agency compelling conformity upon the scene acts in political ways, not only allowing one colleague, at a glance, to be up to speed on a client's situation, but the conformity also acts as a form of consistency-practising what one preaches-whereupon a client can see how success is achieved when all employees fall in line. The third is economic in nature. The nature of the product requires specialized sales techniques, and these techniques are put into action in a formulaic manner because statistics bears out the pattern's effects: If we do these steps, in this order, then we get what we want $X \%$ of the time, and this is the most effective technique we have come up with to date. We therefore see an analogue between the consultancy firm's constitution of a platform in political advocacy, meaning that the consultancy firm looks at the world, finds ways to communicate its core message to the world, and then sticks to that message and promulgates it in uniform ways to garner favour with as many clients as possible.

In the case of Amanda's firm, things look different. Whereas Frank's firm offers what we call a political advocate's understanding of a platform, Amanda's firm understands platform as analogous to product of the environment. We shall explain what we mean by this claim.

Amanda's firm offers online training services, and so the scene becomes what dictates the means of agency. The world now is online; the World Wide Web has taken over. Where the web was once merely a means of agency, it has become so ubiquitous as to become a scene unto itself, and, in this sense, the 
web-as-agency has achieved what Frank's firm would like to see for its own form of agency, political advocacy.

The advantages we see in the constitutive effects of this sort of platform are found in its stability. If one is a product of one's environment-or produces products of the environment-then one knows many of the nuances of being in the scene, both of placement and of background. We see this sort of behaviour in Amanda's ability to find information through alternative search practices, and also in her confidence to be able to utilize them properly, as they are merely an extension of the larger scene of the World Wide Web. Also, because of the stability of relying on the scene itself to carry the means of agency, time is not wasted on what might become a fruitless exercise: the product Amanda sells is already tailored to certain potential clients, and not others, and she can sift through the proper ones without wading through companies who would never be worth her while.

The four remaining cases seem to make a balance between creativity and stability, and where we find this balance is in the area of communication. Instead of having an agenda and firmly proclaiming it to the world, or looking at the world and claiming that this is what can be done in the world as it is, the last four examples - those of Ivar, Vegar, John, and HR-360-show us an interplay between scene and agency. Further, they show us how multiple scenes temper agency.

Ivar and John both rely on their former training as a scene: like the World Wide Web, Ivar's medical training and John's military training, though once agencies, have now been constituted as scenic, as an integral part of their background. Ivar combines his medical training with that of the new scene of the Internet to utilize the tools available, and laments that some of his colleagues can't do the same. John does something similar, utilizing his former military training in relation to information gathering so that he can communicate with his boss in a way that makes information accessible. But, though dealing with it differently, Ivar, and John are saying the same thing when constituting their respective platforms: You can't teach an old dog new tricks. Ivar cannot make the newer platform more accessible to those who do not understand the world of the Internet and John cannot give his boss his old intelligence training.

Vegar, instead of translating for other people (an activity Ivar shrugs off, and John welcomes), interprets everything others give him into one standard. All his university departments as well as the individuals who work for them must meet the dictates of the university concerning publication. So where John might take disparate forms of information and translate it to one person, Vegar takes information from many people and departments and funnels it into one pre-approved publication format. This changes the nature of the scene for Vegar. Ivar's or John's multifaceted scene is partially constituted in their backgrounds (medical training and military service, respectively); Vegar's scene is partially constituted through the standards by which he must make everything adhere, and partially by the people and departments for whom he must interpret. The advantage to Vegar's platform is that there is a stable standard by which to judge materials. The disadvantage comes from a seemingly small ability to make political change. 
This is the main similarity between Vegar and HR-360. HR-360 interprets a corporate employee's strengths in relation to corporate needs, and relays the message that who they are is valuable to the company, so long as those strengths match up with the tasks they are given. Like Vegar on a personal level, HR-360 on the corporate level has the ability to make judgements on the basis of the needs of others, but sacrifices the ability to advocate for an alternative means of evaluation.

None of the six examples is necessarily better than the other. Each, to varying degrees, functions in its context. What we are noting here is not a situation of 'better or worse' nearly so much as we are directing attention to the shifting interplay between agency and scene-creativity and stability-that becomes apparent by analysing the term platform when people invoke it in order to explain what they do and how.

\section{Conclusion}

In conclusion, the six cases still have many similarities unifying them. For each, the platform is a discursive structure: it can be captured as a set of rules or as rules of access to a structure. As such it is a force for large-scale coordination and control (McPhee \& Poole, 2001). These cases reaffirm the platform as a structure because it is a 'social object' that is open to interpretation, as are people, events, decisions (Ashforth \& Humphrey, 1997). Structures fabricate a reality that is constituted in real-time interaction (McPhee \& Poole, 2001). The structure standardizes practices on a platform because the rules constituted by the platform protect resources and personal and corporate identities, and provide a means of adhering to legal requirements, all of which make the manipulation of practices easy to train, to bill for, and to control (McPhee, \& Poole, 2001). Yet they also reveal quite diverse balances between creativity and stability when individuals mention a platform as a social object or a concept. In some instances the term platform means nothing more specific than the difference between the platforms of a Mac and a PC. In other cases the term ties electronics to additional features of control and allows for experts to monitor relative correctness of use.

Lastly, in most of our six cases, rather than relying on technology to complete the task, the platform consistently leads to face-to-face communication. For all their ability to control, liberate, comfort, and educate, platforms appear both to result from and to lead to direct interpersonal communication. John, the USAF retiree, completes charts for his boss, then goes to see him in person. Amanda uses the platform to search for people in a process she hopes will culminate in an important and pivotal face-to-face meeting. Ivar, the Norwegian doctor, pits his knowledge of the platform against the resistance his peers. He casts their view as a preference for face-to-face communication in meetings and diagnostic decisions, while also noting that it is meant to foster face-to-face communication between colleagues. Vegar, the Norwegian administrator, maintains the platform for his University, but he also meets people face-to-face to make sure the work is done correctly. These examples of alternation in sequence between technical platform and direct face-to-face communication extend the communication process and add still another component to the structure: the alternation in effect creates structuration (Giddens, 1984). Most importantly, the platform is a structure that adds the physical component of technology to the act of communication, making the message eventful in a way that it could not be if it were merely words on paper 
or something said by a person. This alternation in sequence between platform and face-to-face communication extends the communication process further by providing 'material embodiment' (McPhee and Poole, p. 519) to a communication process that otherwise can be transitory and uncertain. Platforms, in all their instantiations, simultaneously give us the means by which to move, and the grounding in experience to do so. The two culminate in organizational communication to produce an interplay between creativity and stability.

Table 1

$\begin{array}{lllll}\begin{array}{l}\text { Scene } \\ \text { (Stability) }\end{array} & \begin{array}{l}\text { Agency } \\ \text { (Creativity) }\end{array} & \text { Interplay } & \text { Positives } & \text { Negatives }\end{array}$

\begin{tabular}{|c|c|c|c|c|c|}
\hline Frank & $\begin{array}{l}\text { Database for } \\
\text { communicatio } \\
\text { ns storage }\end{array}$ & $\begin{array}{l}\text { Database for } \\
\text { communicatio } \\
\text { ns storage }\end{array}$ & $\begin{array}{l}\text { Agency is } \\
\text { dictated by } \\
\text { Scene. }\end{array}$ & Reliable. & $\begin{array}{l}\text { Innovation } \\
\text { stagnates }\end{array}$ \\
\hline Amanda & The Internet & The Internet & $\begin{array}{l}\text { Scene is } \\
\text { dictated by } \\
\text { Agency }\end{array}$ & Reliable. & $\begin{array}{l}\text { Innovation } \\
\text { offline goes } \\
\text { unnoticed }\end{array}$ \\
\hline Ivar & $\begin{array}{l}\text { Previous } \\
\text { medical } \\
\text { training }\end{array}$ & $\begin{array}{l}\text { Technological } \\
\text { communicatio } \\
\text { ns: Internet } \\
\text { and intranets }\end{array}$ & $\begin{array}{l}\text { Medical } \\
\text { training and } \\
\text { technological } \\
\text { use dictate } \\
\text { what can be } \\
\text { done }\end{array}$ & $\begin{array}{l}\text { One can do } \\
\text { more and } \\
\text { keep up with } \\
\text { the times }\end{array}$ & $\begin{array}{l}\text { Multiple } \\
\text { platforms } \\
\text { create } \\
\text { confusion }\end{array}$ \\
\hline John & $\begin{array}{l}\text { Previous } \\
\text { military } \\
\text { training }\end{array}$ & $\begin{array}{l}\text { Technological } \\
\text { expertise }\end{array}$ & $\begin{array}{l}\text { Scene and } \\
\text { Agency } \\
\text { combine to } \\
\text { create } \\
\text { unique } \\
\text { abilities }\end{array}$ & $\begin{array}{l}\text { Creative, } \\
\text { functional, } \\
\text { enigmatic }\end{array}$ & $\begin{array}{l}\text { Un- } \\
\text { teachable, } \\
\text { idiosyncratic, } \\
\text { agency } \\
\text { cannot be } \\
\text { transferred }\end{array}$ \\
\hline Vegar & $\begin{array}{l}\text { University } \\
\text { boards and } \\
\text { regulations. } \\
\text { University } \\
\text { departments }\end{array}$ & $\begin{array}{l}\text { Standardized } \\
\text { layout of } \\
\text { published } \\
\text { documents }\end{array}$ & $\begin{array}{l}\text { Scene and } \\
\text { Agency } \\
\text { standardize } \\
\text { processes }\end{array}$ & $\begin{array}{l}\text { Immediately } \\
\text { recognizable } \\
\text {. Repetition } \\
\text { creates } \\
\text { recognition }\end{array}$ & $\begin{array}{l}\text { Multiple } \\
\text { scenes } \\
\text { equate to } \\
\text { constant } \\
\text { interpretation }\end{array}$ \\
\hline HR-360 & $\begin{array}{l}\text { Corporate } \\
\text { clients and } \\
\text { their } \\
\text { individual } \\
\text { employees }\end{array}$ & $\begin{array}{l}\text { Testing and } \\
\text { documentation } \\
\text { of corporate } \\
\text { competency }\end{array}$ & $\begin{array}{l}\text { Agency is } \\
\text { dictated by } \\
\text { Scene }\end{array}$ & $\begin{array}{l}\text { Functional. } \\
\text { HR-360 } \\
\text { remains in } \\
\text { business }\end{array}$ & $\begin{array}{l}\text { Agency is } \\
\text { relegated to } \\
\text { following } \\
\text { trends. }\end{array}$ \\
\hline
\end{tabular}




\section{References}

Ashforth, B. E., \& Humphrey, R. H. (1997). The ubiquity and potency of labeling in organizations. Organization Science, 8(1), 43-58.

Browning, L. D., \& Morris, G. H. (2012). Stories Of life in the workplace: An open architecture for organizational narratology. New York: Routledge.

Burke, K. (1969). A Grammar of Motives. Berkley: University of California Press.

Burke, K. (1931). Counter-statement. Berkeley: University of California Press.

Ciborra, C. U. (1996). The platform organization: Recombining strategies, structures, and surprises. Organization Science, 7(2), 103-118.

Consoli, D., \& Patrucco, P. P. (2008). Innovation platforms and the governance of knowledge: Evidence from Italy and the UK. Economics of Innovation and New Technology, 17(7), 699-716.

Gawer, A. (2010). The organization of technological platforms. In N. Phillips, G. Sewell \& D. Griffiths (Eds.), Technology and Organization: Essays in Honour of Joan Woodward (Research in the Sociology of Organizations, Volume 29) (pp. 287296). Emerald Publishing Group Ltd.

Glaser, B. G., \& Strauss, A. L. (2011). The discovery of grounded theory: strategies for qualitative research. (6th ed.). New Brunswick: Aldine Transaction.

Hirschman, A. O. (1970). Exit, voice, and loyalty: Responses to decline in firms, organizations, and states. Cambridge, MA: Harvard University Press.

Jolly, V. K. (1997). Commercializing new technologies: Getting from mind to market. Boston: Harvard Business School Press.

McPhee, R. D., \& Poole, M. S. (2001). Organizational structures and configurations. In F. Jablin \& L. Putnam (Eds.), The new handbook of organizational communication: Advances in theory, research, and methods (pp. 503-543). Thousand Oaks: Sage Publications.

Online etymology dictionary. (n.d.). Retrieved from http://www.etymonline.com/index.php?term=platform

Orlikowski, W. J. (2009). The sociomateriality of organisational life: considering technology in management research. Cambridge Journal of Economics, 34, 125-141.

Porter, M. E. (1995, May 15). The rise of the urban entrepreneur. Inc., Retrieved from http://www.inc.com/magazine/19950515/2695.html

Ravasi, D., \& Schultz, M. (2006). Responding to organizational identity threats: Exploring the role of organizational culture. Academy of Management Journal, 49(3), 433-458.

Sköld, M., \& Karlsson, C. (2007). Multibranded platform development: A corporate strategy with multimanagerial challenges. Journal of Product Innovation Management, 24(6), 554-566.

van den Hoonaard, W. C. (1997). Working with sensitizing concepts: Analyzing field research. Thousand Oaks, CA: Sage Publishing.

Waters, J. K. (2005, December 30). Word of the year? Application Development Trends. Retrieved August 23, 2006 from http://www.adtmag.com/article.aspx?id=17744 
Von Hippel, E., \& Von Krogh, G. (2003). Open source software and the 'privatecollective' innovation model. Organization Science, 14(2), 209-223. 